\title{
Escolha de genitores quanto à precocidade e produtividade de feijão tipo carioca
}

\author{
Naine Martins do Vale(1), Leiri Daiane Barili(1), Henrique Morais de Oliveira(1), José Eustáquio de Souza Carneiro ${ }^{(1)}$, \\ Pedro Crescêncio Souza Carneiro(1) e Felipe Lopes da Silva ${ }^{(1)}$ \\ (1)Universidade Federal de Viçosa, Departamento de Fitotecnia, Programa de Pós-Graduação em Genética e Melhoramento, Avenida \\ P. H. Rolfs, s/no, CEP 36570-900 Viçosa, MG, Brasil. E-mail: nainemartinsdovale@hotmail.com, leyridaianabarili@hotmail.com, \\ henrique.morais.oliveira@hotmail.com, jesc@ufv.br, carneiro@ufv.br, felipe.silva@ufv.br
}

Resumo - O objetivo deste trabalho foi avaliar linhagens de feijoeiro promissoras para a seleção de genitores com características de feijão tipo carioca, precoces e de alto potencial produtivo. Avaliaram-se 35 linhagens de feijoeiro, em delineamento de blocos ao acaso com três repetições. Quatro destas linhagens - Goiano Precoce, XAN112, Carioca1070 e Rosinha Precoce - foram selecionadas para compor o grupo 1 do dialelo parcial $4 \times 5$, e três - RP1, VC15 e VC33, de ciclo normal, grãos tipo carioca e elevado potencial produtivo - foram utilizadas para compor o grupo 2 do dialelo, juntamente com as cultivares BRSMG Madrepérola e BRS Estilo. Obtiveram-se 20 híbridos que, com seus genitores, foram avaliados na safra da seca de 2013, em Coimbra e Viçosa, MG, em delineamento de blocos ao acaso, com três repetições. A linhagem Goiano Precoce destacouse quanto à precocidade, com valores de capacidade geral de combinação (CGC) negativos e significativos em Viçosa $(-3,15)$ e Coimbra $(-3,44)$. A linhagem RP1 destacou-se quanto ao rendimento de grãos, com valores positivos e significativos de CGC em Viçosa (115) e Coimbra (260). Com base na CGC, a linhagem Goiano Precoce é promissora para utilização como genitora quanto à precocidade, e a RP1, quanto ao aumento no rendimento de grãos.

Termos para indexação: Phaseolus vulgaris, análise dialélica, dialelo parcial.

\section{Choice of parents for earliness and yield of carioca-type bean}

\begin{abstract}
The objective of this work was to evaluate promising bean lines for the selection of parents, with carioca grain-type traits, early, and with high productive potential. Thirty-five common bean lines were evaluated in a randomized complete block design with three replicates. Four of these lines - Goiano Precoce, XAN112, Carioca1070, and Rosinha Precoce - were used to compose the group 1 of a $4 \times 5$ partial diallel, and three - RP1, VC15 e VC33, of normal cycle and carioca grain type with high yield potential - were used to compose the group 2 of the diallel, together with the cultivars BRSMG Mandrepérola and BRS Estilo. Twenty hybrids were obtained, which were evaluated with their parents in the dry season of 2013, in Coimbra and Viçosa, in the state of Minas Gerais, Brazil, in a randomized complete block design with three replicates. Goiano Precoce line stood out for earliness with negative and significant values of general combining ability (GCA), in Viçosa (-3.15) and Coimbra (-3.44). RP1 line stood out for grain yield with positive and significant GCA values, in Viçosa (115) and Coimbra (260). Based on the GCA, Goiano Precoce is a promising line to be used as a parent for earliness, and RP1 for grain yield increase.
\end{abstract}

Index terms: Phaseolus vulgaris, diallel analysis, partial diallel.

\section{Introdução}

O número de dias da emergência ao florescimento é a característica que tem sido utilizada pelos melhoristas para avaliar a precocidade em feijoeiro (Ribeiro et al., 2004; Silva et al., 2007). Este caráter apresenta alta herdabilidade, além de correlação positiva e de elevada magnitude com a maturação fisiológica dos grãos (Santos \& Vencovsky, 1985).
O feijão está entre as espécies de importância econômica com menor período entre a emergência e o florescimento, que varia de 28 a 49 (Ribeiro et al., 2004) ou de 27 a 42 (Buratto et al., 2007) dias. A extensão do ciclo tem sido um dos motivos para o cultivo do feijão sob irrigação e em rotação e sucessão de culturas, em até três épocas do ano (Araújo \& Ferreira, 2006). Mesmo assim, a busca por cultivares mais precoces tem merecido a atenção dos 
melhoristas de feijoeiro (Tulmann Neto \& Sabino, 1994; Buratto et al., 2007).

Cultivares de feijão precoce, em condições normais e com chuvas bem distribuídas, produzem menos do que as de ciclo normal, porém, seu uso em determinadas situações apresenta vantagens. No período das águas, o cultivo das precoces minimiza os riscos de coincidir a floração com o período de altas temperaturas e a colheita com o período chuvoso (Paula Júnior et al., 2010); ainda, segundo estes autores, no cultivo da seca, as cultivares precoces podem produzir mais do que as de ciclo normal, quando as chuvas se concentram mais na fase inicial da cultura. Entretanto, cultivares de feijão mais precoces se adequam mais ao cultivo de outono-inverno (Paula Júnior et al., 2013).

O feijão carioca tem grande aceitação no Brasil e representa $52 \%$ da área cultivada (Brasil, 2014). Entretanto, são poucas as cultivares de grãos tipo carioca que associam precocidade, produtividade $\mathrm{e}$ padrão comercial de grão. Grande parte das fontes de genes quanto à precocidade estão em feijões de origem andina (Welsh et al., 1995), e grãos com padrão comercial, de modo geral, são de origem mesoamericana. Em alguns cruzamentos entre os dois conjuntos gênicos, observa-se incompatibilidade, o que inviabiliza ou causa diversas anormalidades nas plantas $F_{1}$, tais como nanismo, folhas cloróticas, esterilidade, crescimento radical reduzido e formação de raízes adventícias no hipocótilo (Arantes et al., 2008).

Em um programa de melhoramento de plantas autógamas, a escolha de genitores para a obtenção de populações segregantes promissoras é etapa crucial, pois dela depende o sucesso das etapas subsequentes no desenvolvimento de linhagens superiores. Neste contexto, os cruzamentos dialélicos se destacam na seleção de genitores e, em particular, os dialelos parciais, quando o objetivo é reunir fenótipos favoráveis que se encontram em grupos distintos de genitores, pois, nesse caso, não são de interesse as combinações dentro de cada grupo. Os dialelos parciais têm sido utilizados em diversas culturas, como trigo (Pimentel et al., 2013), tomate (Pádua et al., 2010) e feijão (Silva et al., 2013).

O objetivo deste trabalho foi avaliar linhagens de feijoeiro promissoras para a seleção de genitores, com as características de feijão tipo carioca, precoces e de alto potencial produtivo.

\section{Material e Métodos}

Trinta e cinco linhagens de feijoeiro foram avaliadas quanto à produtividade e à precocidade (dias da emergência ao florescimento, DEF). As avaliações foram realizadas na Estação Experimental de Coimbra, do Departamento de Fitotecnia da Universidade Federal de Viçosa, na safra da seca de 2012, no Munícipio de Coimbra, $\mathrm{MG}$, a $20^{\circ} 45^{\prime} \mathrm{S}, 42^{\circ} 51^{\prime} \mathrm{W}$, a $690 \mathrm{~m}$ de altitude. Utilizou-se o delineamento de blocos ao acaso com três repetições; as parcelas constituíram-se de quatro linhas de $4 \mathrm{~m}$ de comprimento, espaçadas de $0,5 \mathrm{~m}$.

A adubação e os tratos culturais foram feitos de acordo com o recomendado para a cultura na região. $\mathrm{O}$ DEF foi avaliado pelo número de dias decorridos da emergência ao florescimento, atingido quando $50 \%$ das plantas da parcela estivesem com pelo menos uma flor aberta. A produtividade de grãos foi obtida com a massa total dos grãos da parcela $(\mathrm{g})$, corrigida para $13 \%$ de umidade e, posteriormente, convertida para $\mathrm{kg} \mathrm{ha}^{-1}$. Os dados obtidos foram submetidos à análise de variância, e as médias agrupadas pelo teste de Scott Knott.

Das 35 linhagens avaliadas, quatro linhagens precoces - Goiano Precoce, XAN112, Carioca1070 e Rosinha Precoce -, pertencentes a diferentes grupos comerciais, foram selecionadas para compor o grupo 1 do dialelo parcial $4 \times 5$. Três linhagens de ciclo normal (RP1, VC15 e VC33), de grãos tipo carioca e elevado potencial produtivo compuseram o grupo 2 do dialelo, juntamente com as cultivares BRSMG Madrepérola e BRS Estilo (não avaliadas no experimento anterior), também de grãos tipo carioca e elevado potencial produtivo. De cada uma das quatro linhagens do grupo 1 e das cinco linhagens do grupo 2 , selecionaramse dez sementes para o dialelo parcial $4 \times 5$, que foram semeadas em seis vasos com capacidade de $10 \mathrm{~L}$, que continha uma mistura, à proporção de $4: 1$, de solo com esterco. O desbaste foi efetuado, a fim de manter duas plantas por vaso. Para alcançar a quantidade suficiente de sementes $F_{1}$ e garantir a sincronia no florescimento, o plantio foi realizado de forma escalonada. Primeiramente, semearam-se as linhagens do grupo 2 (ciclo normal) e, após sete dias, as linhagens do grupo 1 (ciclo precoce). Dez dias após a semeadura, o procedimento foi repetido. Os cruzamentos foram realizados com o procedimento sem emasculação, descrito por Peternelli et al. (2009). 
As sementes $F_{1}$ foram semeadas no campo juntamente com os genitores (20 híbridos e mais 9 genitores). Os experimentos foram implantados em duas localidades no Estado de Minas Gerais - Estação Experimental de Coimbra e Estação Experimental Horta Nova -, em Viçosa, MG $\left(20^{\circ} 45^{\prime} 14 " \mathrm{~S}\right.$, $\left.42^{\circ} 52^{\prime} 55^{\prime \prime} \mathrm{W}\right)$, em março, safra da seca de 2013. Utilizou-se o delineamento de blocos ao acaso com três repetições. As parcelas constituíram-se de duas linhas de $1 \mathrm{~m}$, espaçadas de $0,50 \mathrm{~m}$, com 10 sementes por metro. A adubação e os tratos culturais, bem como as características avaliadas DEF e produtividade foram os mesmos do experimento de avaliação das linhagens anteriormente descrito.

A análise do dialelo foi realizada de acordo com o modelo proposto por Griffing (1956), adaptado a dialelo parcial por Geraldi \& Miranda Filho (1988). O efeito de tratamento (médias dos 20 híbridos e 9 genitores), considerado como fixo, foi decomposto em capacidade geral (CGC) e específica de combinação (CEC); o efeito de ambientes foi considerado como aleatório.

$\mathrm{O}$ modelo estatístico utilizado no presente trabalho foi: $Y_{i j}=\mu+1 / 2\left(d_{1}+d_{2}\right)+g_{i}+g_{j}^{\prime}+s_{i j}+\bar{\varepsilon}_{i j}$ em que: $Y_{i j}$ é a média do cruzamento do i-ésimo progenitor do grupo 1 com o j-ésimo progenitor do grupo $2 ; \mathrm{Y}_{\mathrm{i} 0}$ é a média do i-ésimo progenitor do grupo $1(\mathrm{i}=0,1$, ...p); $\mathrm{Y}_{0 \mathrm{j}}$ é a média do j-ésimo progenitor do grupo $2(\mathrm{j}$ $=0,1, \ldots q) ; \mathrm{m}$ é a média geral do dialelo; $\mathrm{d}_{1}$ e $\mathrm{d}_{2}$ são os contrastes das médias dos grupos 1 e 2 e da média geral; $g_{\mathrm{i}}$ é o efeito da capacidade geral de combinação do i-ésimo progenitor do grupo 1 ; $\mathrm{g}_{\mathrm{j}}$ é o efeito da capacidade geral de combinação do j-ésimo progenitor do grupo $2 ; \mathrm{s}_{\mathrm{ij}}$ é o efeito da capacidade específica de combinação; e $\bar{\varepsilon}_{\mathrm{ij}}$ é o erro experimental médio.

A herança das características DEF e produtividade de grãos foram inferidas por meio da relação das somas de quadrados entre as CGC (grupos $1+2$ ) e a CEC, pois o quadrado médio não apresenta decomposição ortogonal. A soma dos quadrados dos tratamentos foi desdobrada em soma de quadrados para a capacidade geral de combinação (CGC), capacidade específica de combinação (CEC) e grupos.

As análises foram realizadas com o auxílio do Programa Genes (Cruz, 2013).

\section{Resultados e Discussão}

Houve efeito significativo de linhagens quanto às características dias decorridos entre a emergência e o florescimento (DEF) e produtividade de grãos (Tabela 1), o que é uma indicação da existência de diferenças genéticas entre as linhagens para as duas características em questão.

Observou-se a formação de três grupos, em que as seguintes linhagens foram consideradas precoces: Rosinha MT, Capixaba Precoce, VC31, IAPAR57, CNFRJ Precoce, CFE46, CFE48, 1090067-8, XAN 112, Carioca 1070, Bola Enxofre, Vermelhão, RP2, Radiante, Iraí, CFE134, Preto 60 Dias, Rosinha Precoce, Carnaval, CFE35, CFE39, Goiano Precoce (Tabela 2). O DEF das linhagens apresentou variação de 28 a 49 dias, semelhantemente ao relatado por Ribeiro et al. (2004) e Buratto et al. (2007), que observaram DEF de 28 a 43 dias. A seleção de genitores, com florescimento precoce para compor o dialelo, potencializa a obtenção de populações segregantes promissoras para o desenvolvimento de linhagens superiores quanto à precocidade.

Observou-se efeito significativo de tratamentos (linhagens e cultivares) quanto às características DEF e produtividade de grãos nos dois ambientes, Coimbra e Viçosa (Tabela 3), o que evidencia a presença de variabilidade genética entre os genitores e híbridos para as duas características avaliadas.

Houve efeito significativo de capacidade geral de combinação (CGC) tanto do grupo 1 quanto do grupo 2, exceto para a DEF do grupo 2, em Coimbra, e de CEC nas características DEF e produtividade, nos dois ambientes (Tabela 3). As somas de quadrados da CEC foi superior às somas de quadrados das CGC (grupos 1 e 2) quanto à produtividade, tanto em Coimbra quanto Viçosa, o que indica haver predominância de efeitos não aditivos no controle desta característica. Quanto

Tabela 1. Resumo das análises de variância, quanto ao número de dias decorridos entre a emergência e o florescimento (DEF) e quanto à produtividade de grãos, referentes à avaliação de 35 linhagens de feijão em Coimbra, MG, na safra da seca de 2012.

\begin{tabular}{lccc}
\hline Fonte de variação & GL & \multicolumn{2}{c}{ QM } \\
\cline { 3 - 4 } & & DEF & Produtividade $\left(\mathrm{kg} \mathrm{ha}^{-1}\right)$ \\
\hline Bloco & 2 & 20,06 & 305.487 \\
Linhagens & 34 & $60,37^{* *}$ & $891.613^{* *}$ \\
Resíduo & 68 & 10,48 & 241.942 \\
\hline Média & - & 40,50 & 2.702 \\
CV $(\%)$ & - & 8,5 & 16,3 \\
\hline
\end{tabular}

${ }^{* *}$ Significativo a $1 \%$ de probabilidade, pelo teste $\mathrm{F}$. 
ao DEF, houve predominância de efeitos aditivos em Coimbra e não aditivos em Viçosa. Predominância de efeitos gênicos aditivos em cultura do feijoeiro, no controle do ciclo, foi relatada por Ramalho et al. (1993). Quanto à produtividade de grãos, não há consenso, pois, alguns autores relatam predominância de efeitos aditivos (Moreto et al., 2007), enquanto

Tabela 2. Média do número de dias decorridos, entre a emergência e o florescimento (DEF), e produtividade de grãos de 35 linhagens de feijão, avaliadas em Coimbra, MG, na safra da seca em $2012^{(1)}$.

\begin{tabular}{llc}
\hline Linhagem & DEF & Produtividade $\left(\mathrm{kg} \mathrm{ha}^{-1}\right)$ \\
\hline Amendoim 1 & $49 \mathrm{a}$ & $2.602 \mathrm{~b}$ \\
VC30 & $47 \mathrm{a}$ & $3.854 \mathrm{a}$ \\
CFE54 & $46 \mathrm{a}$ & $3.391 \mathrm{a}$ \\
CFE91 & $46 \mathrm{a}$ & $2.072 \mathrm{~b}$ \\
VC20 & $46 \mathrm{a}$ & $3.540 \mathrm{a}$ \\
RP1 & $46 \mathrm{a}$ & $3.538 \mathrm{a}$ \\
Pintado Bolinha & $45 \mathrm{a}$ & $3.298 \mathrm{a}$ \\
Amendoim & $45 \mathrm{a}$ & $1.808 \mathrm{~b}$ \\
VC15 & $45 \mathrm{a}$ & $2.892 \mathrm{a}$ \\
VC33 & $44 \mathrm{a}$ & $2.952 \mathrm{a}$ \\
Safira & $44 \mathrm{a}$ & $3.048 \mathrm{a}$ \\
VC32 & $43 \mathrm{a}$ & $3.178 \mathrm{a}$ \\
CFE56 & $43 \mathrm{a}$ & $2.257 \mathrm{~b}$ \\
Rosinha MT & $41 \mathrm{~b}$ & $2.357 \mathrm{~b}$ \\
Capixaba Precoce & $41 \mathrm{~b}$ & $2.909 \mathrm{a}$ \\
VC31 & $41 \mathrm{~b}$ & $3.540 \mathrm{a}$ \\
IAPAR57 & $40 \mathrm{~b}$ & $3.286 \mathrm{a}$ \\
CNFRJ Precoce & $40 \mathrm{~b}$ & $1.954 \mathrm{~b}$ \\
CFE46 & $40 \mathrm{~b}$ & $2.878 \mathrm{a}$ \\
CFE48 & $40 \mathrm{~b}$ & $2.419 \mathrm{~b}$ \\
1090067-8 & $39 \mathrm{~b}$ & $3.397 \mathrm{a}$ \\
XAN112 & $39 \mathrm{~b}$ & $3.087 \mathrm{a}$ \\
Carioca1070 & $38 \mathrm{~b}$ & $2.446 \mathrm{~b}$ \\
Bola Enxofre & $38 \mathrm{~b}$ & $2.687 \mathrm{~b}$ \\
Vermelhão & $38 \mathrm{~b}$ & $2.343 \mathrm{~b}$ \\
RP2 & $38 \mathrm{~b}$ & $3.498 \mathrm{a}$ \\
Radiante & $37 \mathrm{~b}$ & $2.290 \mathrm{~b}$ \\
Irai & $37 \mathrm{~b}$ & $2.546 \mathrm{~b}$ \\
CFE134 & $37 \mathrm{~b}$ & $1.867 \mathrm{~b}$ \\
Preto 60 dias & $37 \mathrm{~b}$ & $2.446 \mathrm{~b}$ \\
Rosinha Precoce & $36 \mathrm{~b}$ & $2.594 \mathrm{~b}$ \\
Carnaval & $36 \mathrm{~b}$ & $2.559 \mathrm{~b}$ \\
CFE35 & $2.843 \mathrm{a}$ \\
CFE39 & $2.489 \mathrm{~b}$ \\
Goiano Precoce & $1.973 \mathrm{~b}$ \\
\hline
\end{tabular}

(1)Médias seguidas de letras iguais, nas colunas, não diferem entre si, pelo teste de Scott Knott, a 5\% de probabilidade. outros relatam predominância de efeitos não aditivos (Pereira et al., 2007). A variância aditiva é a principal fonte de variação genética explorada pela maioria dos programas de melhoramento, o que possibilita êxito da seleção nas gerações iniciais (Isik \& Frampton, 2003).

$\mathrm{Na}$ análise conjunta (Tabela 3), os efeitos de tratamentos, de CGC (grupos 1 e 2), de CEC e de ambientes não foram significativos, tanto em relação ao DEF quanto à produtividade, com exceção de CGC do grupo 1 para DEF. Todas as interações com ambientes foram significativas, o que é uma indicação de que os genes que participam do controle genético das características DEF e produtividade se expressam de forma diferente em Coimbra e Viçosa. Assim, a escolha dos potenciais genitores deve considerar as estimativas dos efeitos em cada um dos ambientes. Características governadas por muitos genes (quantitativos), de modo geral, apresentam grande influência ambiental, como as características ciclo (Ribeiro et al., 2004) e produtividade de grãos (Araújo et al., 2012). Mendes et al. (2009) avaliaram populações segregantes de feijão quanto ao DEF e detectaram expressiva interação genótipos x ambientes. Faria et al. (2009) avaliaram vinte cultivares de feijão e detectaram grande influência do ambiente na expressão fenotípica da produtividade de grãos.

$\mathrm{Na}$ seleção de populações segregantes por meio do dialelo, a escolha é realizada com base nas estimativas da CGC e da CEC, em que se busca identificar populações cujos genitores apresentem elevada estimativa dessas capacidades, ou seja, genitores que proporcionem a obtenção de populações segregantes que apresentem média alta e variabilidade genética de magnitude expressiva, parâmetros fundamentais em uma população destinada à extração de linhas puras (Ramalho et al., 2012).

Em relação às estimativas de CGC dos genitores do grupo 1, quanto a dias entre a emergência e o florescimento (Tabela 4), a linhagem Goiano Precoce destacou-se com os maiores valores negativos e significativos, em Coimbra $(-3,13)$ e Viçosa $(-3,44)$, tendo-se destacado também na análise conjunta $(-3,29)$, o que é uma indicação de sua superioridade quanto à frequência de alelos para a redução de DEF relativamente às demais linhagens. Nas estimativas de CGC dos genitores do grupo 2, em que a CGC foi significativa apenas em Viçosa, destacaram-se as 
linhagens RP1 $(-2,00)$ e VC15 $(-1,87)$, com valores significativos. $\mathrm{Na}$ análise conjunta, nenhum genitor apresentou valor negativo e significativo. Quando se deseja reduzir a média de uma característica, pelo

Tabela 3. Quadrado médio das análises de variância individuais e conjunta, para os caracteres dias decorridos entre a emergência e o florescimento (DEF) e produtividade de grãos, referentes à avaliação de nove genitores e $20 \mathrm{~F}_{1}$, em Coimbra e Viçosa, MG, na safra da seca de 2013.

\begin{tabular}{|c|c|c|c|c|c|c|c|}
\hline \multirow[t]{2}{*}{ Fonte de variação } & \multirow[t]{2}{*}{ GL } & \multicolumn{2}{|c|}{ Coimbra } & \multicolumn{2}{|c|}{ Viçosa } & \multicolumn{2}{|c|}{ Conjunta } \\
\hline & & $\mathrm{DEF}$ & $\begin{array}{l}\text { Produtividade } \\
\quad\left(\mathrm{kg} \mathrm{ha}^{-1}\right)\end{array}$ & DEF & $\begin{array}{l}\text { Produtividade } \\
\left(\mathrm{kg} \mathrm{ha}^{-1}\right)\end{array}$ & $\mathrm{DEF}$ & $\begin{array}{l}\text { Produtividade } \\
\left(\mathrm{kg} \mathrm{ha}^{-1}\right)\end{array}$ \\
\hline Tratamento & 28 & $46,27^{* *}$ & $943.408^{* *}$ & $146,68 * *$ & $745.751 * *$ & $97,85^{\text {ns }}$ & $818.280^{\mathrm{ns}}$ \\
\hline Grupo & 1 & $484,94 * *$ & $6.529 .532 * *$ & $468,39 * *$ & $139.089^{\text {ns }}$ & $07,00^{\mathrm{ns}}$ & $2.381 .321^{*}$ \\
\hline CGC I & 3 & $169,11 * *$ & $1.590 .122 * *$ & $132,75 * *$ & $892.643 *$ & $283,48^{*}$ & $1.343 .529^{\mathrm{ns}}$ \\
\hline CGC II & 4 & $6,45^{\mathrm{ns}}$ & $377.695^{*}$ & $127,87^{* *}$ & $944.356^{*}$ & $49,81^{\mathrm{ns}}$ & $570.338^{\text {ns }}$ \\
\hline CEC & 20 & $13,87 * *$ & $680.237 * *$ & $136,44 * *$ & $714.330 * *$ & $84,50^{\mathrm{ns}}$ & $710.929^{\text {ns }}$ \\
\hline Ambiente & 1 & - & - & - & - & $0,31^{\mathrm{ns}}$ & $526^{\mathrm{ns}}$ \\
\hline Tratamento $\mathrm{x}$ ambiente & 28 & - & - & - & - & $95,10 * *$ & $870.879 * *$ \\
\hline Grupos $\mathrm{x}$ ambiente & 1 & - & - & - & - & $953,23 * *$ & 4.287.299** \\
\hline CGC I x ambiente & 3 & - & - & - & - & $18,37 * *$ & $1.139 .236^{* *}$ \\
\hline CGC II x ambiente & 4 & - & - & - & - & $84,50 *$ & $751.713 * *$ \\
\hline CEC $\mathrm{x}$ ambiente & 20 & - & - & - & - & $65,70 * *$ & $683.638^{* *}$ \\
\hline Resíduo $^{(1)}$ & 56 e 112 & 5,16 & 144.247 & 7,00 & 302.604 & 6,00 & 223.425 \\
\hline Média & 28 & 37,36 & 2336 & 40,52 & 2187 & 38,94 & 2261 \\
\hline CV $(\%)$ & 1 & 6,2 & 16,4 & 9,1 & 25,4 & 8,7 & 20,2 \\
\hline
\end{tabular}

${ }^{n}$ Não significativo. * e **Significativo a 5 e $1 \%$ de probabilidade, respectivamente, pelo teste $\mathrm{F} .{ }^{(1)} 56$, valor para os locais Coimbra e Viçosa e 112 , valor para análise conjunta.

Tabela 4. Estimativas dos efeitos da capacidade geral de combinação (CGC) de linhagens de genitores de feijoeiro e da capacidade específica de combinação (CEC) de seus 20 híbridos $F_{1}$, avaliados quanto aos dias decorridos entre a emergência e o florescimento (DEF), em Coimbra e Viçosa, MG, na safra da seca de 2013.

\begin{tabular}{|c|c|c|c|c|c|c|}
\hline \multirow[t]{2}{*}{ Genitor $^{(1)}$} & \multicolumn{5}{|c|}{$\mathrm{CEC}$} & \multirow[t]{2}{*}{ CGC 1} \\
\hline & RP1 & $\mathrm{VC} 15$ & VC33 & BRSMG Madrepérola & BRS Estilo & \\
\hline & \multicolumn{6}{|c|}{ Coimbra } \\
\hline Goiano Precoce & $-5,06 * *$ & $1,30^{\mathrm{ns}}$ & $-0,06^{\mathrm{ns}}$ & $1,18^{\mathrm{ns}}$ & $0,06^{\mathrm{ns}}$ & $-3,44 * *$ \\
\hline XAN112 & $0,93^{\mathrm{ns}}$ & $-0,69^{\text {ns }}$ & $-1,06^{\text {ns }}$ & $-3,81 * *$ & $0,06^{\mathrm{ns}}$ & $2,5 * *$ \\
\hline Carioca 1070 & $1,04^{\mathrm{ns}}$ & $1,42^{\text {ns }}$ & $-0,95^{\text {ns }}$ & $-0,70^{\mathrm{ns}}$ & $2,04^{\mathrm{ns}}$ & $0,44^{\mathrm{ns}}$ \\
\hline Rosinha Precoce & $2,04^{\mathrm{ns}}$ & $-0,57^{\mathrm{ns}}$ & $3,04 * *$ & $-0,70^{\text {ns }}$ & $1,04^{\mathrm{ns}}$ & $0,45^{\mathrm{ns}}$ \\
\hline \multirow[t]{2}{*}{ CGC 2} & $-0,27^{\text {ns }}$ & $0,35^{\text {ns }}$ & $-0,27^{\text {ns }}$ & $-0,52^{\text {ns }}$ & $0,71^{\mathrm{ns}}$ & \\
\hline & \multicolumn{6}{|c|}{ Viçosa } \\
\hline Goiano Precoce & $3,58^{\mathrm{ns}}$ & $3,45^{\mathrm{ns}}$ & $-2,04^{\mathrm{ns}}$ & $0,20^{\mathrm{ns}}$ & $5,70 * *$ & $-3,13 * *$ \\
\hline XAN112 & $4,24 * *$ & $4,12^{\mathrm{ns}}$ & $-2,37^{\mathrm{ns}}$ & $-1,12^{\mathrm{ns}}$ & $3,37^{\mathrm{ns}}$ & $1,19^{\text {ns }}$ \\
\hline Carioca 1070 & $7,58 * *$ & $10,45^{* *}$ & $1,95^{\mathrm{ns}}$ & $-2,70^{\text {ns }}$ & $1,70^{\text {ns }}$ & $1,86 * *$ \\
\hline Rosinha Precoce & $3,35^{\text {ns }}$ & $3,23^{\mathrm{ns}}$ & $-2,26^{\mathrm{ns}}$ & $-2,01^{\text {ns }}$ & $9,48 * *$ & $0,08^{\mathrm{ns}}$ \\
\hline \multirow[t]{2}{*}{ CGC 2} & $-2,00 * *$ & $-1,87 * *$ & $2,62 * *$ & $2,37 * *$ & $-1,12^{\mathrm{ns}}$ & \\
\hline & \multicolumn{6}{|c|}{ Conjunta } \\
\hline Goiano Precoce & $-0,74^{\mathrm{ns}}$ & $2,38 *$ & $-1,05^{\text {ns }}$ & $0,69^{\mathrm{ns}}$ & $2,82 * *$ & $-3,29 * *$ \\
\hline XAN112 & $2,59 *$ & $1,71 *$ & $-1,72 *$ & $-2,47 *$ & $1,65^{*}$ & $1,87^{*}$ \\
\hline Carioca 1070 & $4,31 * *$ & $5,93 * *$ & $0,50^{\mathrm{ns}}$ & $1,74^{\mathrm{ns}}$ & $1,87^{*}$ & $1,15^{\mathrm{ns}}$ \\
\hline Rosinha Precoce & $2,70^{*}$ & $1,13^{\mathrm{ns}}$ & $-0,39^{\text {ns }}$ & $-0,36^{\mathrm{ns}}$ & $5,26 * *$ & $0,26^{\mathrm{ns}}$ \\
\hline CGC 2 & $-1,13^{\text {ns }}$ & $-0,76^{\mathrm{ns}}$ & $1,17^{\mathrm{ns}}$ & $0,92^{\mathrm{ns}}$ & $-0,20^{\mathrm{ns}}$ & \\
\hline
\end{tabular}

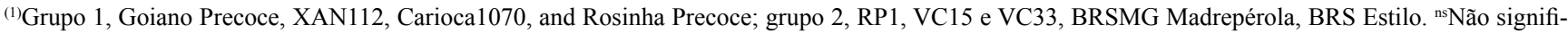

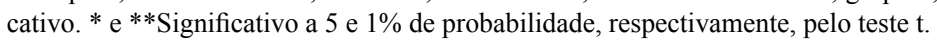


menos um dos genitores deve apresentar valor negativo (Krause et al., 2012).

Com base nas estimativas da CGC quanto à produtividade (Tabela 5), tem-se que, em Coimbra, nenhuma linhagem do grupo 1 contribuiu com alelos favoráveis para o aumento da produção, porém ,a linhagem Rosinha Precoce apresentou valor positivo e significativo em Viçosa (270) e na análise conjunta (167). No grupo 2, somente RP1 apresentou valores positivos e significativos, em Coimbra (115), Viçosa (269) e na análise conjunta (188), o que evidencia a concentração de alelos favoráveis ao aumento da produtividade.

Para a determinação das combinações mais promissoras quanto ao DEF, cabe ressaltar que, dos cruzamentos da Goiano Precoce com RP1 e VC15, apenas a combinação Goiano Precoce/RP1 apresentou CEC negativa e significativa. $\mathrm{Na}$ análise conjunta, nenhuma combinação com a Goiano Precoce apresentou CEC negativa e significativa. A combinação Goiano Precoce/RP1 apresentou DEF de 29 dias em Coimbra (Tabela 6) e 33 dias em Viçosa, o que é inferior à linhagem RP1 tanto em Coimbra (39) quanto em Viçosa (41), porém similar à Goiano Precoce, em Coimbra
(27) e Viçosa (30). As médias de DEF são indicativas de que nenhuma linhagem conseguiu complementar os genes quanto à precocidade, encontrados na Goiano Precoce, pois nenhum híbrido apresentou DEF menor do que o desta linhagem. No entanto, a combinação com RP1 produziu um híbrido com DEF desejável, o que pode favorecer a seleção de plantas precoces nessa população. Ribeiro et al. (2004) verificaram que a combinação de genitores precoces possibilitou a obtenção de população $F_{2}$ precoce.

Quanto à produtividade de grãos, quando se consideram as linhagens com alta CGC e também a CEC, a combinação mais promissora foi Rosinha Precoce/RP1, em Coimbra. Em Viçosa, apesar de esta combinação não apresentar CEC significativa, mesmo com elevada magnitude (432), essas duas linhagens tiveram CGC positiva e significativa. O híbrido Rosinha Precoce/RP1 mostrou-se promissor nos dois ambientes avaliados, bem como apresentou média de rendimento de grãos superior à de seus genitores em Coimbra (3.085 kg ha-1) e em Viçosa (3.091 kg ha-1) (Tabela 6), o que mostra a divergência e complementariedade de genes quanto à produtividade desses genitores.

Tabela 5. Estimativas dos efeitos da capacidade geral de combinação (CGC) de linhagens de genitores de feijoeiro e da capacidade específica de combinação (CEC) de seus 20 híbridos $\mathrm{F}_{1}$, quanto à produtividade de grãos $\left(\mathrm{kg} \mathrm{ha}^{-1}\right)$, em Coimbra $\mathrm{e}$ Viçosa, MG, na safra da seca de 2013.

\begin{tabular}{|c|c|c|c|c|c|c|}
\hline \multirow[t]{2}{*}{ Genitor $^{(1)}$} & \multicolumn{5}{|c|}{ CEC } & \multirow[t]{2}{*}{ CGC } \\
\hline & RP1 & VC15 & VC33 & BRSMG Madrepérola & BRS Estilo & \\
\hline \multicolumn{7}{|c|}{ Coimbra } \\
\hline Goiano Precoce & $-1222 * *$ & $394^{\mathrm{ns}}$ & $254^{\mathrm{ns}}$ & $588 * *$ & $85^{\mathrm{ns}}$ & $-358 *$ \\
\hline XAN112 & $240^{\text {ns }}$ & $98^{\text {ns }}$ & $-192^{\mathrm{ns}}$ & $119^{\mathrm{ns}}$ & $183^{\mathrm{ns}}$ & $168^{\mathrm{ns}}$ \\
\hline Carioca 1070 & $108^{\mathrm{ns}}$ & $197^{\mathrm{ns}}$ & $195^{\mathrm{ns}}$ & $-173^{\mathrm{ns}}$ & $316^{\mathrm{ns}}$ & $125^{\mathrm{ns}}$ \\
\hline Rosinha Precoce & $696 * *$ & $212^{\mathrm{ns}}$ & $498 *$ & $-100^{\mathrm{ns}}$ & $189^{\mathrm{ns}}$ & $65^{\mathrm{ns}}$ \\
\hline CGC 2 & $115^{*}$ & $85^{\mathrm{ns}}$ & $-55^{\mathrm{ns}}$ & $-190 *$ & $45^{\mathrm{ns}}$ & \\
\hline \multicolumn{7}{|c|}{ Viçosa } \\
\hline Goiano Precoce & $16^{\mathrm{ns}}$ & $-516^{\mathrm{ns}}$ & $-881 * *$ & $339^{\text {ns }}$ & $126^{\mathrm{ns}}$ & $-68^{\mathrm{ns}}$ \\
\hline XAN112 & $20^{\mathrm{ns}}$ & $-181^{\mathrm{ns}}$ & $-117^{\mathrm{ns}}$ & $195^{\mathrm{ns}}$ & $-95^{\mathrm{ns}}$ & $-121^{\mathrm{ns}}$ \\
\hline Carioca 1070 & $-239^{\text {ns }}$ & $-681^{*}$ & $397^{\mathrm{ns}}$ & $133^{\mathrm{ns}}$ & $-284^{\mathrm{ns}}$ & $-81^{\text {ns }}$ \\
\hline Rosinha Precoce & $432^{\mathrm{ns}}$ & $-439^{\text {ns }}$ & $884 * *$ & $-23^{\text {ns }}$ & $39^{\text {ns }}$ & $270 *$ \\
\hline CGC 2 & $260 *$ & $-254 *$ & $47^{\mathrm{ns}}$ & $74^{\mathrm{ns}}$ & $-127^{\mathrm{ns}}$ & \\
\hline \multicolumn{7}{|c|}{ Conjunta } \\
\hline Goiano Precoce & $-602 * *$ & $-61^{\mathrm{ns}}$ & $-313 *$ & $463 * *$ & $105^{\mathrm{ns}}$ & $-213^{*}$ \\
\hline XAN112 & $130^{\mathrm{ns}}$ & $-41^{\mathrm{ns}}$ & $-155^{\mathrm{ns}}$ & $157^{\mathrm{ns}}$ & $43^{\mathrm{ns}}$ & $23^{\mathrm{ns}}$ \\
\hline Carioca 1070 & $-65^{\mathrm{ns}}$ & $-241 *$ & $296^{*}$ & $29^{\mathrm{ns}}$ & $16^{\mathrm{ns}}$ & $22^{\mathrm{ns}}$ \\
\hline Rosinha Precoce & $564 * *$ & $-113^{\mathrm{ns}}$ & $691 * *$ & $-62^{\mathrm{ns}}$ & $114^{\mathrm{ns}}$ & $167 *$ \\
\hline CGC 2 & $188^{*}$ & $-84^{\mathrm{ns}}$ & $-6^{\mathrm{ns}}$ & $-57^{\mathrm{ns}}$ & $-39^{\text {ns }}$ & \\
\hline
\end{tabular}

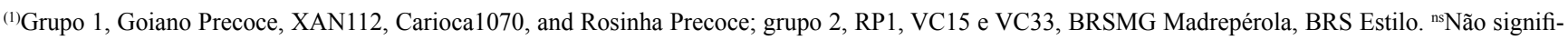
cativo. * e**Significativo a 5 e $1 \%$ de probabilidade, respectivamente, pelo teste $\mathrm{t}$. 
A CGC da Goiano Precoce, quanto aos dias entre a emergência e o florescimento, e a CGC da RP1, quanto à produtividade de grãos, são evidências da concentração de alelos favoráveis destas linhagens, que contribuem para a melhoria destas características. Esses resultados se repetiram nos dois ambientes, assim como as médias dessas características, o que é uma indicação de estabilidade dessas linhagens. A cultura do feijão é submetida a uma diversidade de

Tabela 6. Médias de nove linhagens e seus 20 híbridos $\mathrm{F}_{1}$, quanto ao número de dias decorridos da emergência ao florescimento (DEF) e quanto à produtividade de grãos $\left(\mathrm{kg} \mathrm{ha}^{-1}\right)$, em Coimbra e Viçosa, MG, na safra da seca de 2013.

\begin{tabular}{|c|c|c|c|c|}
\hline \multirow[t]{2}{*}{ Tratamento } & \multicolumn{2}{|c|}{ Coimbra } & \multicolumn{2}{|r|}{ Viçosa } \\
\hline & $\overline{D E F}$ & rodutividade & $\overline{\mathrm{DEF}}$ & Produtividade \\
\hline \multicolumn{5}{|l|}{ Grupo 1} \\
\hline Goiano precoce & 27 & 1.949 & 30 & 2.521 \\
\hline XAN112 & 37 & 1.827 & 40 & 2.046 \\
\hline Carioca1070 & 32 & 1.645 & 34 & 2.324 \\
\hline Rosinha Precoce & 31 & 1.797 & 35 & 2.294 \\
\hline Grupo 2 & 39 & 3.021 & 41 & 2.462 \\
\hline RP1 & 39 & 3.021 & 41 & 2.462 \\
\hline VC15 & 36 & 2.421 & 39 & 2.455 \\
\hline $\mathrm{VC} 33$ & 40 & 2.203 & 43 & 2.009 \\
\hline BRSMG Madrepérola & 42 & 2.104 & 42 & 1.833 \\
\hline BRS Estilo & 37 & 2.412 & 39 & 1.906 \\
\hline \multicolumn{5}{|l|}{ Híbridos F1 } \\
\hline RP1/Goiano precoce & 29 & 2.232 & 33 & 2.337 \\
\hline RP1/XAN112 & 40 & 2.733 & 43 & 2.288 \\
\hline RP1/Carioca1070 & 38 & 2.558 & 43 & 2.067 \\
\hline RP1/Rosinha Precoce & 39 & 3.085 & 41 & 3.091 \\
\hline VC15/Goiano precoce & 35 & 2.330 & 38 & 1.888 \\
\hline VC15/XAN112 & 39 & 2.561 & 43 & 2.570 \\
\hline VC15/Carioca1070 & 38 & 2.618 & 44 & 2.009 \\
\hline VC15/Rosinha Precoce & 37 & 2.572 & 41 & 2.003 \\
\hline VC33/Goiano precoce & 33 & 2.045 & 37 & 1.924 \\
\hline VC33/XAN112 & 38 & 2.124 & 41 & 1.936 \\
\hline VC33/Carioca1070 & 36 & 2.470 & 36 & 2.491 \\
\hline VC33/ Rosinha Precoce & 40 & 2.712 & 40 & 3.330 \\
\hline BRSMG MP/Goiano precoce & 34 & 2.248 & 39 & 2.473 \\
\hline BRSMG MP/XAN112 & 35 & 2.306 & 42 & 2.276 \\
\hline BRSMG MP/Carioca1070 & 36 & 1.970 & 41 & 2.354 \\
\hline BRSMG MP/Rosinha Precoce & 36 & 1.982 & 42 & 2.449 \\
\hline BRS Estilo/Goiano precoce & 34 & 1.985 & 39 & 2.057 \\
\hline BRS Estilo/XAN 112 & 40 & 2.609 & 43 & 2.182 \\
\hline BRS Estilo/Carioca 1070 & 40 & 2.700 & 42 & 1.933 \\
\hline BRS Estilo/Rosinha Precoce & 39 & 2.512 & 41 & 2.309 \\
\hline
\end{tabular}

condições ambientais, o que contribui para que ocorra interação cultivares x ambientes (Faria et al., 2009). Assim, cultivares precoces, além de alta produtividade de grãos, devem ter um comportamento previsível e responder aos estímulos propostos pelo ambiente.

Com base nas estimativas das capacidades geral e específica de combinação e nas médias, selecionaramse duas combinações híbridas promissoras quanto à precocidade e produtividade de grãos: Goiano Precoce/ RP1 e Rosinha Precoce/RP1, que apresentaram, respectivamente, baixo valor de DEF e alto valor de produtividade de grãos. No entanto, nenhuma combinação reuniu precocidade e alto potencial produtivo.

\section{Conclusão}

1. Com base na capacidade geral de combinação, Goiano Precoce é a cultivar promissora para ser utilizada como genitora quanto à precocidade, e a RP1 como genitora quanto ao incremento no rendimento de grãos.

2. Não foi identificada nenhuma combinação que reunisse precocidade e alto potencial produtivo.

\section{Agradecimentos}

Ao Conselho Nacional de Desenvolvimento Científico e Tecnológico (CNPq) e à Fundação de Amparo à Pesquisa do Estado de Minas Gerais (Fapemig), pelo apoio financeiro.

\section{Referências}

ARANTES, L. de O.; RAMALHO, M.A.P.; ABREU, Â. de F.B. Controle genético da incompatibilidade do cruzamento entre cultivares andinas e mesoamericanas de feijoeiro comum. Ciência e Agrotecnologia, v.32, p.978-980, 2008. DOI: 10.1590/ S1413-70542008000300041.

ARAÚJO, G.A.A.; FERREIRA, A.C.B. Manejo do solo e plantio. In: VIEIRA, C.; PAULA JÚNIOR, T.J.; BORÉM, A. Feijão. 2.ed. Viçosa: Ed. da UFV, 2006. p.87-114.

ARAÚJO, L.C. de; GRAVINA, G. de A.; MARINHO, C.D.; ALMEIDA, S.N.C.; DAHER, R.F.; AMARAL, J.A.T. Contribution of components of production on snap bean yield. Crop Breeding and Applied Biotechnology, v.12, p.206-210, 2012. DOI: 10.1590/ S1984-70332012000300007.

BRASIL. Ministério da Agricultura. Perfil do feijão no Brasil. Disponível em: <http:/www.agricultura.gov.br/vegetal/culturas/ feijao/saiba-mais>. Acesso em: 1 maio 2014. 
BURATTO, J.S.; MODA-CIRINO, V.; FONSECA JÚNIOR, N.S.; PRETE, C.E.C.; FARIA, R.T. de. Adaptabilidade e estabilidade produtiva em genótipos precoces de feijão no Estado do Paraná. Semina: Ciências Agrárias, v.28, p.373-380, 2007. DOI: 10.5433/1679-0359.2007v28n3p373.

CRUZ, C.D. Genes - a software package for analysis in experimental statistics and quantitative genetics. Acta Scientiarum. Agronomy, v.35, p.271-276, 2013. DOI: 10.4025/actasciagron.v35i3.21251.

FARIA, A.P.; MODA-CIRINO, V.; BURATTO, J.S.; SILVA, C.F.B. da; DESTRO, D. Interação genótipo x ambiente na produtividade de grãos de linhagens e cultivares de feijão. Acta Scientiarum. Agronomy, v.31, p.579-585, 2009. DOI: 10.4025/actasciagron. v31i4.850.

GERALDI, I.O.; MIRANDA-FILHO, J.B. Adapted models for the analysis of combining ability of varieties in partial diallel crosses. Revista Brasileira de Genética, v.11, p.419-430, 1988.

GRIFFING, B. Concept of general and specific combining ability in relation to diallell crossing systems. Australian Journal of Biological Sciences, v.9, p.463-493, 1956.

ISIK, F.; LI, B.; FRAMPTON, J. Estimates of additive, dominance and epistatic genetic variances from a clonally replicated test of loblolly pine. Forest Science, v.49, p.77-88, 2003.

KRAUSE, W.; RODRIGUES, R.; LEAL, N.R. Capacidade combinatória para características agronômicas em feijão-de-vagem. Revista Ciência Agronômica, v.43, p.522-531, 2012. DOI: 10.1590/S1806-66902012000300015.

MENDES, F.F.; RAMALHO, M.A.P.; ABREU, Â. de F.B. Índice de seleção para escolha de populações segregantes de feijoeiro-comum. Pesquisa Agropecuária Brasileira, v.44, p.1312-1318, 2009. DOI: 10.1590/S0100-204X2009001000015.

MORETO, A.L.; RAMALHO, M.A.P.; NUNES, J.A.R.; ABREU, Â. de F.B. Estimação dos componentes da variância fenotípica em feijoeiro utilizando o método genealógico. Ciência e Agrotecnologia, v.31, p.1035-1042, 2007. DOI: 10.1590/ S1413-70542007000400014.

PÁDUA, T.R.P. de; GOMES, L.A.A.; MALUF, W.R.; CARVALHO FILHO, J.L.S. de; GONÇALVES NETO, A.C.; ANDRADE, M.C. Capacidade combinatória de híbridos de tomateiro de crescimento determinado, resistentes a Begomovirus e Tospovirus. Pesquisa Agropecuária Brasileira, v.45, p.818-825, 2010. DOI: 10.1590/ S0100-204X2010000800007.

PAULA JÚNIOR, T.J. de; CARNEIRO, J.E. de S.; VIEIRA, R.F.; ABREU, A. de F.B.; RAMALHO, M.A.P.; DEL PELOSO, M.J.; TEIXEIRA, H. Cultivares de feijão-comum para Minas Gerais. Belo Horizonte: Epamig, 2010. 40p.

PAULA JÚNIOR, T.J. de; VIEIRA, R.F.; CARNEIRO, J.E.S.; RAMALHO, M.A.; ABREU, A.F.B.; LIMA, R.C.; LEHNER, M.S. O programa de melhoramento do feijoeiro-comum no Estado de Minas Gerais. In: GRUPO DE ESTUDOS AVANÇADOS EM FITOPATOLOGIA. Melhoramento genético no manejo de doenças de plantas. Visconde do Rio Branco: Suprema, 2013.

PEREIRA, H.S.; SANTOS, J.B. dos; ABREU, Â. de F.B.; COUTO, K.R. Informações fenotípicas e marcadores microssatélites de QTL na escolha de populações segregantes de feijoeiro. Pesquisa Agropecuária Brasileira, v.42, p.707-713, 2007. DOI: 10.1590/ S0100-204X2007000500014.

PETERNELLI, L.A.; BORÉM, A.; CARNEIRO, J.E.S. Hibridação em feijão. In: BORÉM, A. (Ed.). Hibridação artificial de plantas. 2.ed. Viçosa: Ed. da UFV, 2009. p.514-536.

PIMENTEL, A.J.B.; RIBEIRO, G.; SOUZA, M.A. de; MOURA, L.M.; ASSIS, J.C. de; MACHADO, J.C. Comparação de métodos de seleção de genitores e populações segregantes aplicados ao melhoramento de trigo. Bragantia, v.72, p.113-121, 2013. DOI: $10.1590 /$ S0006-87052013005000026.

RAMALHO, M.A.P.; ABREU, Â. de F.B.; SANTOS, J.B. dos. Desempenho de progênies precoces de feijoeiro (Phaseolus vulgaris L.) em diferentes locais e épocas de plantio. Revista Ceres, v.40, p.272-280, 1993.

RAMALHO, M.A.P.; ABREU, Â. de F.B.; SANTOS, J.B. dos; NUNES, J.A.R. Aplicações da genética quantitativa no melhoramento de plantas autógamas. Lavras: Ed. da UFLA, 2012. 522p.

RIBEIRO, N.D.; HOFFMANN JUNIOR, L.; POSSEBON, S.B. Variabilidade genética para ciclo em feijão dos grupos preto e carioca. Revista Brasileira de Agrociência, v.10, p.19-29, 2004.

SANTOS, J.B. dos; VENCOVSKY, R. Controle genético do início do florescimento em feijoeiro. Pesquisa Agropecuária Brasileira, v.20, p.841-845, 1985.

SILVA, F.B.; RAMALHO, M.A.P.; ABREU, Â. de F.B. Seleção recorrente fenotípica para florescimento precoce de feijoeiro 'Carioca'. Pesquisa Agropecuária Brasileira, v.42, p.1437-1442, 2007. DOI: 10.1590/S0100-204X2007001000010.

SILVA, V.M.P. e; CARNEIRO, P.C.S.; MENEZES JÚNIOR, J.Â.N. de; CARNEIRO, V.Q.; CARNEIRO, J.E. de S.; CRUZ, C.D.; BORÉM, A. Genetic potential of common bean parents for plant architecture improvement. Scientia Agricola, v.70, p.167-175, 2013. DOI: $10.1590 / \mathrm{S} 0103-90162013000300005$.

TULMANN NETO, A.; SABINO, J.C. Indução e uso de mutante de hábito determinado e precoce em feijoeiro (Phaseolus vulgaris L.). Revista Brasileira de Genética, v.17, p.425-430, 1994.

WELSH, W.; BUSHUK, W.; ROCA, W.; SINGH, S.P. Characterization of agronomic traits and markers of recombinant inbred lines from intra- and interracial populations of Phaseolus vulgaris L. Theoretical and Applied Genetics, v.91, p.169-177, 1995.

Recebido em 13 de agosto de 2014 e aprovado em 24 de novembro de 2014

Pesq. agropec. bras., Brasília, v.50, n.2, p.141-148, fev. 2015

DOI: $10.1590 / \mathrm{S} 0100-204 X 2015000200006$ 